IP Periodica Polytechnica

Mechanical Engineering

\author{
62(1), pp. 16-25, 2018 \\ https://doi.org/10.3311/PPme.10613
}

Creative Commons Attribution (1)

RESEARCH ARTICLE

\section{Numerical Analysis of Thermal and Aerodynamic Fields in a Channel with Cascaded Baffles}

\author{
Younes Menni ${ }^{*}$, Ahmed Azzi ${ }^{1}$
}

Received 11 February 2017; accepted after revision 12 December 2017

\begin{abstract}
A computational fluid dynamic analysis of thermal and aerodynamic fields for an incompressible steady-state flow of a Newtonian fluid through a two-dimensional horizontal rectangular section channel with upper and lower wall-attached, vertical, staggered, transverse, cascaded rectangular-triangular (CRT), solid-type baffles is carried out in the present paper using the Commercial, Computational Fluid Dynamics, software FLUENT. The flow model is governed by the Reynolds averaged Navier-Stokes (RANS) equations with the SST $k$ - $\omega$ turbulence model and the energy equation. The finite volume method (FVM) with the SIMPLE-discretization algorithm is applied for the solution of the problem. The computations are carried out in the turbulent regime for different Reynolds numbers. In this study, thermo-aeraulic fields, dimensionless axial profiles of velocity, skin friction coefficients, local and average heat transfer coefficients, and thermal enhancement factor were investigated, at constant surface temperature condition along the heated upper wall of the channel, for all the geometry under investigation and chosen for various stations. The impact of the cascaded rectangular-triangular geometry of the baffle on the thermal and dynamic behavior of air is shown and this in comparing the data of this obstacle type with those of the simple flat rectangular-shaped baffle. This CFD analysis can be a real application in the field of heat exchangers, solar air collectors, and electronic equipments.
\end{abstract}

\section{Keywords}

cascaded baffle, CFD, heat transfer, turbulent flow, simulation

\footnotetext{
${ }^{1}$ Unit of Research on Materials and Renewable Energies URMER, Department of Physics, Faculty of Sciences,

Abou Bekr Belkaid University,

BP 119-13000-Tlemcen, Algeria

"Corresponding author, e-mail: menniyounes@gmail.com
}

\section{Introduction}

The topic is of paramount importance. Heat exchangers are used in several sectors and in very diverse fields. The improvement of their performance has been and is still of major concern to theorists and practitioners. In general, in order to achieve high energy performances, it is essential to install rows of staggered or in-line, transverse or longitudinal, vertical or inclined, simple, corrugated or shaped, and solid, perforated or porous baffles and fins within the flow channel in the heat exchangers so as to create turbulence and also to lengthen the trajectory of fluids by promoting a better convective heat exchange. Consequently, a remarkable improvement in the thermal efficiency is obtained.

The first study on the numerical analysis of the features of the flow and forced-convection heat transfer in periodically varying cross section ducts was reported by Patankar et al. [1]. The authors exposed the concepts of periodically fully-developed flow and heat transfer. The three-dimensional laminar forced-convection flow was investigated by Guo and Anand [2] in a duct having one single baffle in the intake region. The impact of the Reynolds number, Prandtl number, baffle height and thermal conductivity ratio were examined. A numerical and experimental study was carried out by Demartini et al. [3] on air flow inside a channel with a rectangular cross section with two baffle plates mounted on the upper and lower walls. This study included also a comprehensive investigation of the velocity and pressure profiles. The solution to the problem was found by the Hot Wire Anemometry technique and the Finite Volume method using the commercial program FLUENT 5.2. The fluid flow and heat transfer through staggered wall-mounted two-dimensional obstacles, put on the bottom and top walls of the channel, were attentively examined by Mohammadi Pirouz et al. [4], using the Lattice Boltzmann Method (LBM). The authors concluded that the Lattice Boltzmann Method (LBM) is well suited for studying the heat transfer in conjugate problems. The flow and convective heat transfer characteristics of a three-dimensional square duct with various arrangements of fins in both laminar and turbulent flow were numerically characterized and studied by 
Mokhtari et al. [5]. The results presented showed that efficient fin arrangement highly influences on the cooling performance of the plate. Nasiruddin and Kamran Siddiqui [6] indicated that the convective heat transfer in a heat exchanger tube may be enhanced by placing a baffle inside the tube. The investigators considered a comparative study between three different baffle orientations. The first case examined a vertical baffle. The second case investigated a baffle inclined towards the upstream end, and the third one considered a baffle inclined towards the downstream end. The thermal and dynamic characteristics in the shell side of a shell and tube heat exchanger (STHE) fitted with segmental baffles and different arrangements were numerically analyzed by Mellal et al. [7]. Two primordial parameters were tested: baffles spacing of 106.6, 80 and 64 $\mathrm{mm}$ and six baffles inclination angles of 45, 60, 90, 120, 150 and $180^{\circ}$. Dutta and Hossain [8] experimentally investigated the local heat transfer characteristics and the associated frictional head loss in a rectangular channel with inclined solid and perforated baffles. A combination of two baffles of same overall size was used in their experiment. The upstream baffle was attached to the top heated surface, while the position, orientation, and the shape of the other baffle were varied to identify the optimum configuration for enhanced heat transfer. Guerroudj and Kahalerras [9] simulated the influence of porous block shape on the laminar mixed convective heat transfer and airflow characteristics inside a two-dimensional parallel plate channel when the buoyant and forced flow effects are simultaneously present. The influence of the buoyancy force intensity, the porous blocks shape going from the rectangular shape to the triangular shape, their height, the porous medium permeability, the Reynolds number and the thermal conductivity ratio was analyzed. Other similar works can be found in the literature, i.e, Fodor [10], Rábai and Vad [11], Hegedus et al. [12], Füle and Hernádi [13], Goda and Bánhidi [14], Bidar et al. [15], Khrabry et al. [16], and Fenyvesi and Horváth [17]. The form geometry of the baffle is also a necessary structural parameter for the enhancement of the heat transfer phenomenon inside a channel, for example, 'L'-shaped [18], discrete ' $\mathrm{V}$ ' and ' $\mathrm{V}$ '-orifice [19], double ' $\mathrm{V}$ ' [20], diamond [21], helical [22], waisted triangular [23], and 'Z'-shaped [24].

The present computational fluid dynamic work focuses on the study of an interesting topic from different points of view, i.e. theoretical, practical as well as numerical modelling. This study aims to improve the heat transfer within thermal devices such as heat exchangers and other electronic equipment; these thermal devices play a major role in the industry these days. This work consists of a numerical study of a turbulent air flow, in forced convection, in the presence of two solid-type baffles of cascaded rectangular-triangular form, arranged in an overlapping manner, in a horizontal two-dimensional pipe of rectangular section.

\section{Flow description}

\subsection{Baffle and channel geometry}

The physical geometry considered in this study is a two-dimensional rectangular cross section channel with heated upper and lower wall-mounted solid-type baffles in a periodically staggered manner as presented in more detail in Demartini et al. [3]. Detail of the test channel with the segmented baffles and thermo-aeraulic boundary conditions is presented in Fig. 1. The aspect ratio of channel width-to-height, channel length-to-aeraulic diameter, baffle spacing-to-channel height ratio, and blockage ratio of baffle height-to-channel height are fixed at $W / H=1.321, L / D h=3.317, P i / H=0.972$, and $b / H=0.547$, respectively.

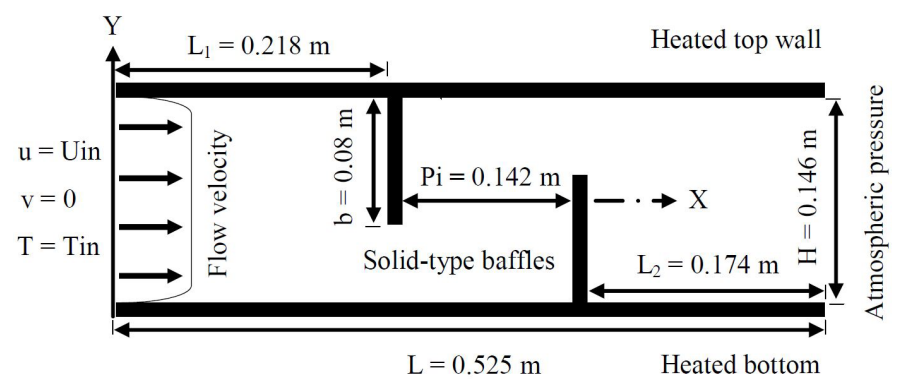

Fig. 1 Solid-type baffled channel geometry with boundary conditions.

The extended baffle geometry under investigation is a cascaded rectangular-triangular baffle (CRTB) as shown in Fig. 2a. It is triangular baffle of height, $a$, in cascade with a rectangular baffle such that the overall height of assembly is $b$, and $a / b$ is fixed at 0.5 . The base thickness of the baffle assembly is assumed to be $w$, equal to $0.01 \mathrm{~m}$

Also, a simple flat rectangular-shaped baffle $(a / b=0)$ pair with the same geometrical dimensions $b$ and $w$ is introduced for comparison, as presented in Fig. 2b. Air is the working medium with the flow rate in terms of Reynolds numbers ranging from 10,000 to 30,000 .

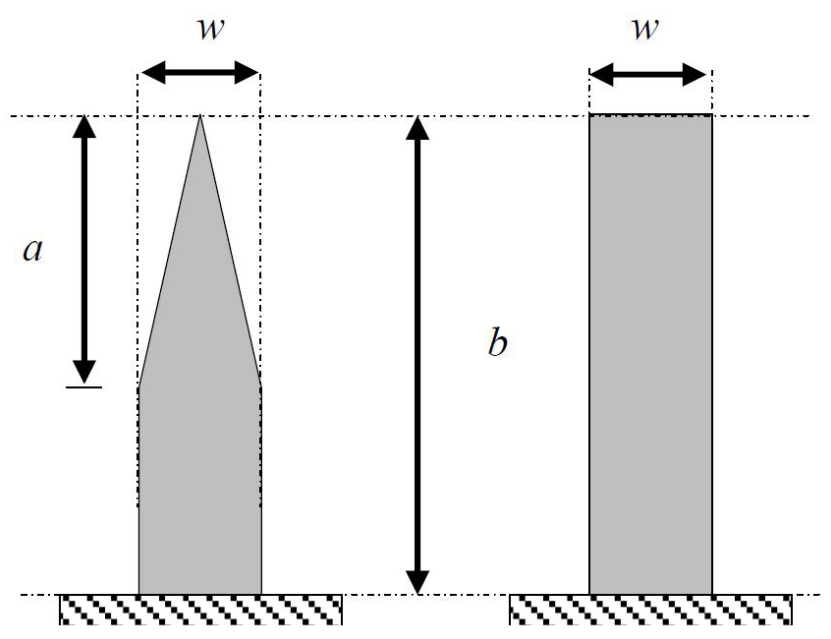

Fig. 2 Shape geometry of the baffle under investigation: a) cascaded rectangular-triangular baffle (CRTB: $a / b=0.5)$ and $b)$ flat rectangular baffle (simple baffle: $a / \mathrm{b}=0$ ). 


\subsection{Assumptions}

These assumptions are: (i) airflow is supposed to be turbulent and under steady-state condition; (ii) flow and heat transfer are two-dimensional; (iii) viscous dissipation and pressure force work are negligible; (iv) the physical properties of fluid and solid are constant; (v) the fluid is Newtonian and incompressible; (vi) the fluid enters the channel with a uniform temperature and constant velocity profile; and (vii) the ShearStress Transport $k-\omega$ model, is used for the closure of the configuration under study.

\subsection{Boundary conditions}

The aerodynamic boundary conditions are set according to the numerical and experimental analysis of Demartini et al. [3] while the thermal boundary conditions are chosen according to the numerical investigation of Nasiruddin and Kamran Siddiqui [6]. A uniform one-dimensional profile of fluid velocity $\left(u=U_{i n}, v=0\right)$ at $27^{\circ} \mathrm{C}(\operatorname{Tin}=300 \mathrm{~K})$ is introduced as the aeraulic boundary condition at the start of the whole domain investigated while an atmospheric pressure $(P=P a t m)$ outlet condition is applied at the channel outlet, as shown in Fig. 1. The inlet turbulence intensity was kept at $I=2 \%$. Impermeable boundary and no-slip wall conditions were implemented over the surfaces of the channel as well as the CRTB surface. And to accurately simulate the flow in the near-wall region, the standard wall function method is used. A constant temperature of $102^{\circ} \mathrm{C}(T w=375 \mathrm{k})$ was applied on the top and bottom surfaces of the channel as the thermal boundary condition. The flow Reynolds number $(\mathrm{Re})$ based on channel aeraulic diameter

$$
D_{h}=2 H W /(H+W)
$$

is given by

$$
\operatorname{Re}=\rho \bar{U} D_{h} / \mu
$$

The skin friction coefficient $\left(C_{f}\right)$ is given by

$$
C_{f}=2 \tau_{w} / \rho \bar{U}^{2}
$$

The friction factor $(f)$ is evaluated from the pressure drop $(\Delta \mathrm{P})$ as

$$
f=2(\Delta P / L) D_{h} / \rho \bar{U}^{2}
$$

where $\bar{U}$ presents the average axial velocity of the section, and $\tau_{w}$ is the shear stress to the wall.

For determining the heat transfer rate inside the channel, the heat transfer is measured by the local Nusselt number $\left(N u_{x}\right)$ which can be written as

$$
N u_{x}=h_{x} D_{h} / k_{f}
$$

and the average Nusselt number $(\mathrm{Nu})$ can be obtained by

$$
N u=\frac{1}{L} \int N u_{x} \partial x
$$

The following expression represents the thermal enhancement factor $(T E F)$ :

$$
T E F=\left(N u / N u_{0}\right) /\left(f / f_{0}\right)^{1 / 3}
$$

The quantities $N u_{0}$ and $f_{0}$ are the average Nusselt number and the friction factor of the smooth channel, respectively.

The Dittus and Boelter correlation has the form [25]:

$$
N u_{0}=0.023 \operatorname{Re}^{0.8} \operatorname{Pr}^{0.4} \text { for } \operatorname{Re} \geq 10^{4}
$$

The Petukhov correlation has the form [26]:

$$
f_{0}=(0.79 \ln \operatorname{Re}-1.64)^{-2} \text { for } 3 \times 10^{3} \leq \operatorname{Re} \leq 5 \times 10^{6}
$$

\section{CFD procedure}

Based on the above assumptions, the flow model in the isothermal wall channel with staggered CRTBs is governed by the Reynolds-averaged Navier-Stokes (RANS) equations with the Shear-Stress Transport (SST) $k$ - $\varepsilon$ turbulence model and the energy equation.

A non-uniform grid system with a large concentration of nodes in regions of steep gradients, such as those close to the walls and baffle plates was employed. The grid independence tests were performed by realizing CFD simulations in the whole domain investigated, using different structured quadrilateral-type grid systems with the number of mesh nodes ranging from 35 to 145 along the pipe depth and 95 to 370 along the length $(95 \times 35 ; 120 \times 45 ; 145 \times 55 ; 170 \times 65 ; 195 \times 75 ; 220$ $\times 85 ; 245 \times 95$; and $370 \times 145$ ), for $R e=8.73 \times 10^{4}$. The grid system with the number of nodes equal to $245 \times 95$ (in $X$ and $Y$ directions respectively) performs around $0.33 \%$, and $0.371 \%$ deviation for the $N u$, and $f$, respectively, in compared with the grid of size $370 \times 145$. Therefore, the grid cell of $245 \times 95$ is selected for the rest of our study.

The wall functions are employed to prescribe the boundary conditions along the faces of the baffle plates and the channel walls in the computational domain. In this study, CFD modelling is performed using the commercial CFD software FLUENT. The finite volume method, developed by Patankar [27], is adopted for the discretization, and all the variables are treated with the Second order upwind scheme [27]. The SIMPLE discretization algorithm [27] was used to solve the pressure-velocity coupling in order to avoid the appearance of irrational pressure field and velocity field. To control the update of the computed variables at each iteration, under-relaxation was varied between 0.3 and 1, as reported in Ref. [6]. The criterions of convergence are set as: relative residual of $10^{-6}$ for the flow and $10^{-9}$ for the energy equation.

The validation of the current numerical simulation is also done in this section. Fig. 3 shows the comparison between the present numerical simulations and the numerical and experimental data of Demartini et al. [3] on the axial profiles of the velocity. The geometry of their problem is a simplification of the 


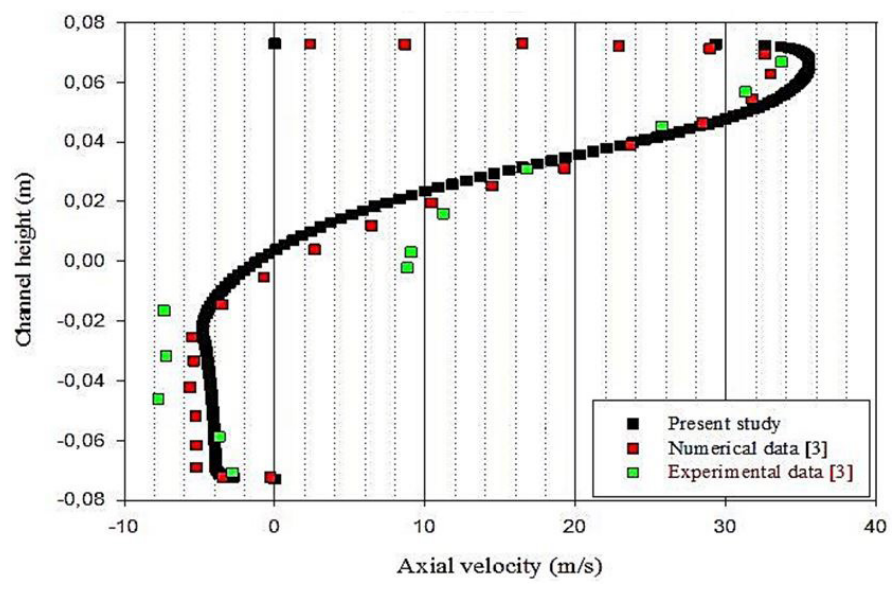

Fig. 3 Validation plot of axial velocity profiles with reported numerical and experimental data [3] at $x=0.525 \mathrm{~m}$ for $\mathrm{Re}=8.73 \times 10^{4}$.

geometry of baffle plates found in shell-and-tube heat exchangers. Both the numerical and experimental axial velocity profiles are computed along the duct height at $\mathrm{Re}=8.73 \times 10^{4} \mathrm{~A}$ comparison of numerical and experimental results of velocity profiles after the second baffle, near the channel outlet is given in Fig. 3. At a position $x=0.525 \mathrm{~m}, 29 \mathrm{~mm}$ before channel outlet, and as shown in this plot of the validation, our numerical results are very agreeable. These results give confidence that the numerical method used was accurate.

\section{Results and discussion}

\subsection{Structure of flow}

The effect of the CRTB $(a / b=0.5)$ on the flow pattern of the near solid surface is reported in this section and this in comparing the results of this type with those of the simple flat rectangular-shaped baffle $(a / b=0)$. For the representation of the figures, $\operatorname{Re}=10,000$ is chosen as base case.

Fig. $4 \mathrm{a}$ and $\mathrm{b}$ shows the magnitude velocity field of air through the channel with $W / H=1.321$ and $\mathrm{Re}=10,000$ for simple and cascaded baffles, respectively. In both cases studied $(a / b=0$ and $a / b=0.5)$, the result analysis shows that the flow is quite disorganized at high air velocity, when hitting obstacles, the disturbance is consistent and it is easy to distinguish three major perturbation regions. In the first zone, immediately upstream of the two baffles, the fluid is accelerated and reaches a velocity in the axial direction, at the approach of the baffle; the streamlines of fluid are deflected. Regarding the second region, located between the end (the top) of each baffle and the channel wall, the flow is characterized by relatively high velocities, approaching values of the order of $440 \%$ of the inlet velocity. This increase is generated by reducing the effect of the passage sections of flow. The air is then accelerated by the effect of contraction. Finally, the third zone is situated downstream of each baffle. The streamlines are generated by the effect of the expansion of the flow out of the section formed by the baffles and the walls. The most important phenomenon in this region lies in the formulation of zone of recirculation of air and with very low

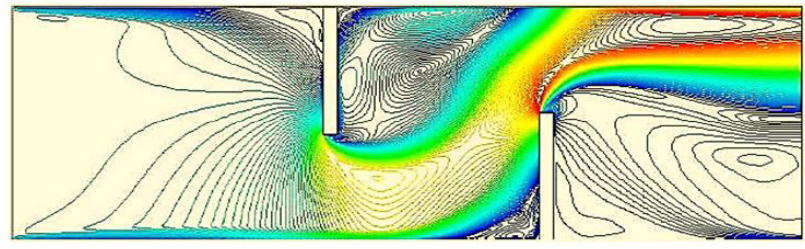

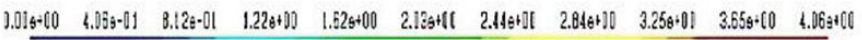

(a)

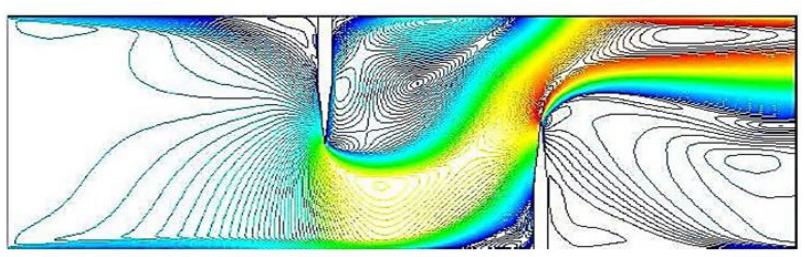

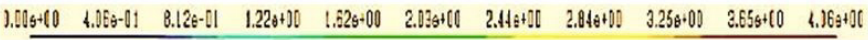

(b)

Fig. 4 Magnitude velocity field distribution along the channel for: a) simple and b) cascaded baffles, $\mathrm{Re}=10,000$

velocity values are observed. The understanding of the effect of each form of baffle simulated can be quantified by plotting the profiles of axial velocities in three regions of the whole domain investigated, upstream, downstream, and between baffles. Velocity values are scaled to the velocity at the entrance $\left(U_{i n}\right)$.

In the two studied cases $(a / b=0$ : simple $)$ and $(a / b=0.5$ : cascaded rectangular-triangular), Fig. 5 shows the profiles of dimensionless axial velocity $\left(U / U_{i n}\right)$ upstream of the first baffle, for two transverse positions at $x=0.159 \mathrm{~m}$ and $x=0.189 \mathrm{~m}$. Can be clearly seen a reduction of axial velocities of the flow in the upper part of the channel approach of the first baffle, while in the free segment the flow is accelerating to the space beneath the next fin to the baffle. The figure also shows that the profile of velocity upstream of the cascaded baffle has dimensions greater than those of the simple baffle.

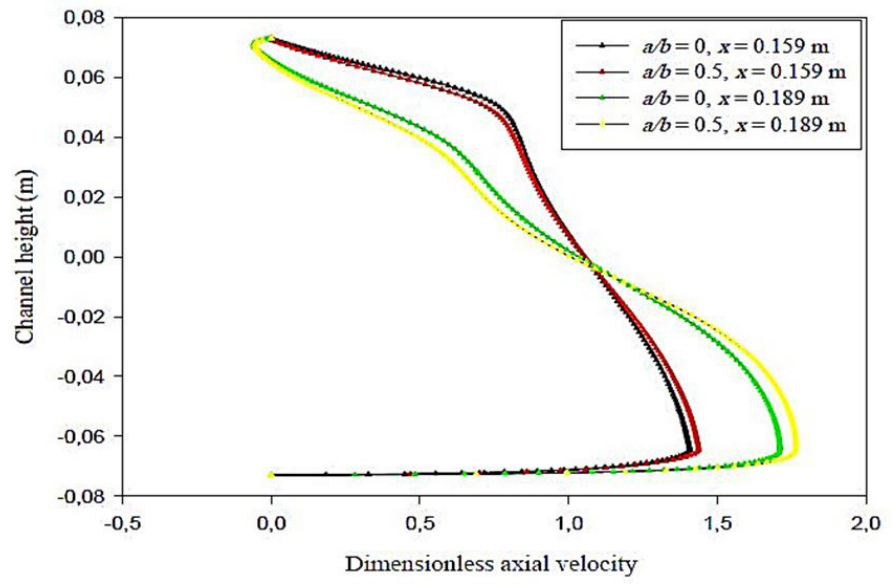

Fig. 5 Profiles of $U / U_{\text {in }}$ upstream of the first baffle, $\operatorname{Re}=10,000$. 
Fig. 6a and $\mathrm{b}$ shows the dimensionless axial velocity profiles $\left(U / U_{i n}\right)$ between the first and the second baffle at distances equal to $0.032 \mathrm{~m}$ and $0.062 \mathrm{~m}$ after the first baffle, corresponding to positions $x=0.255 \mathrm{~m}$ and $x=0.285 \mathrm{~m}$ from the entrance, respectively. In the upper part of the channel, the negative velocities indicate the presence of a recirculation zone downstream of the first baffle, which has been also noticed that the flow is characterized by relatively high speeds in particular in the area between the tip of the fin and the bottom wall of the channel, approaching values of the order of $299 \%$ of the inlet velocity. The velocity value increase with the increase of $a / b$ ratio and thus, the $a / b=0.5$ provides maximum velocity of airflow. The figure also shows that the baffle shape has a significant impact on the recirculation zone length in the region downstream of the first baffle. For both the sections investigated, the maximum recirculation zone length was found at $a / b=0.5$, which decrease with a decrease in $a / b$.

The numerical results presented by the dimensionless axial velocity profiles for the two sections $x=0.315 \mathrm{~m}$ and $x=0.345$ $\mathrm{m}$, are shown in Fig. 7a and b. These positions are located in the intermediate zone upstream of the second baffle. It is noted that the flow approaching the second baffle, its velocity

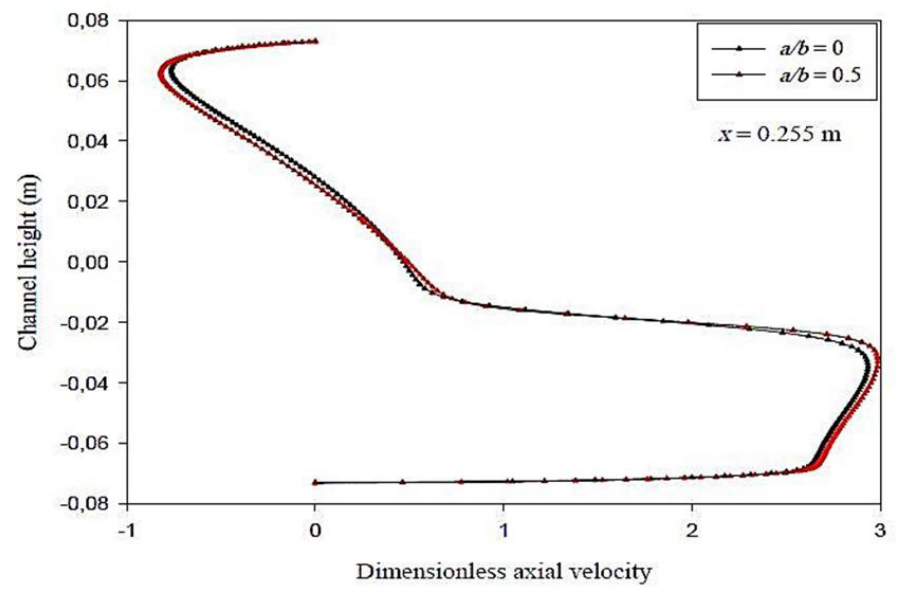

(a)

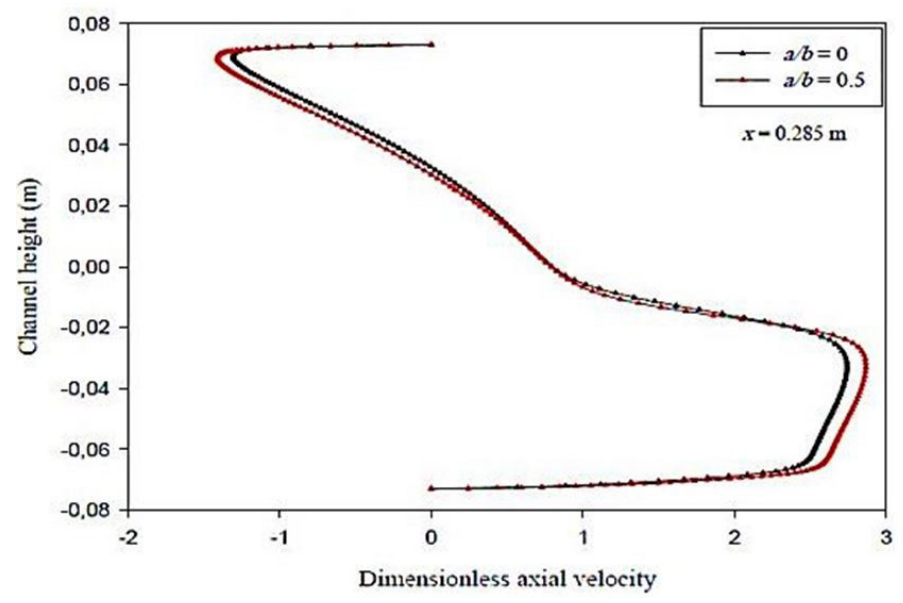

(b)

Fig. 6 Profiles of $U / U_{i n}$ downstream of the first baffle at locations a) $x=0.255 \mathrm{~m}$ and b) $x=0.285 \mathrm{~m}$ from entrance, $\mathrm{Re}=10,000$. is reduced in the lower part of the channel, while in the upper part; the flow begins to accelerate above the second baffle to output. This limitation depends considerably recirculation zones downstream of each baffle. These vortices occur in their neighborhood, grow and increase greatly the flow resistance. These disorderly movements, localized, characterized by negative values observed in Figs. 6 and 8. As expected, the use of a baffle of cascaded form leads to a considerable increase in the axial velocity for both stations analyzed, compared with a simple baffle; the cascading existing at the upper part of the baffle facilities the flow with the mean flow direction which makes it possible to increase the axial component of the velocity and to considerably increase the recirculation zone length.

At the outlet of the channel, at the transverse position $x=0.029 \mathrm{~m}$ before the exit section of the channel, the axial velocity profile is presented in Fig. 8 . When the fluid flows through the section $x=0.525 \mathrm{~m}$, just before the outlet of the channel, the value of the velocity is approximately $3.96 \mathrm{~m} / \mathrm{s}$, or 4.41 times higher than the reference velocity. These values are only possible because of the very high recirculation rearward of the second baffle. It is also noticed that the case of $a / b=0.5$ ensures axial velocities higher than that in the case of $a / b=0$.

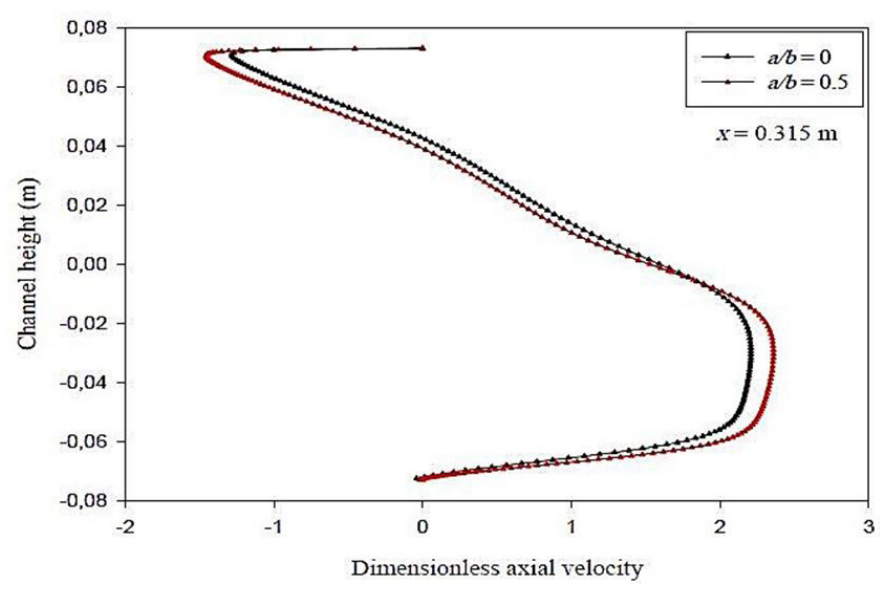

(a)

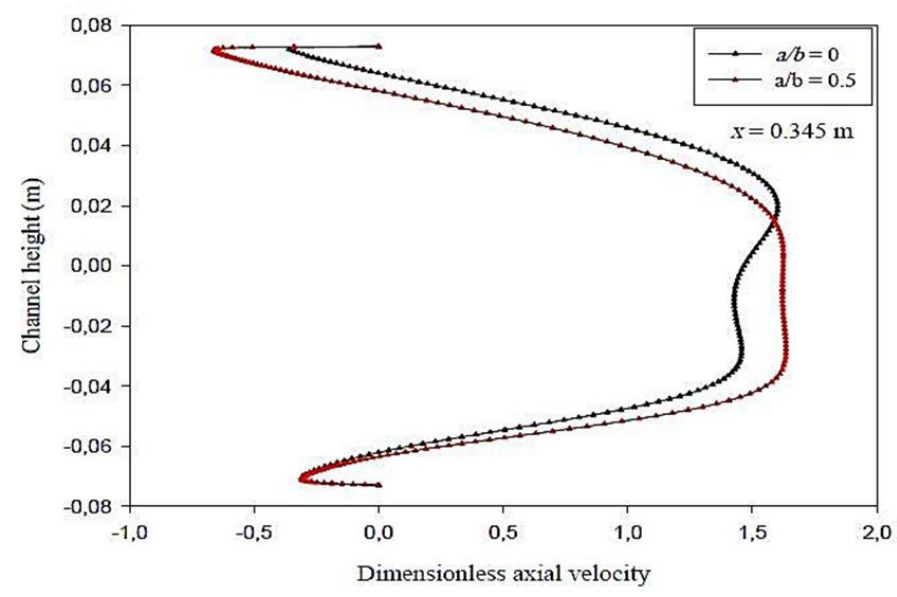

(b)

Fig. 7 Profiles of $U / U_{\text {in }}$ between the baffles for positions a) $x=0.315 \mathrm{~m}$ and b) $x=0.345 \mathrm{~m}$, measured downstream of the entrance, $\mathrm{Re}=10,000$ 


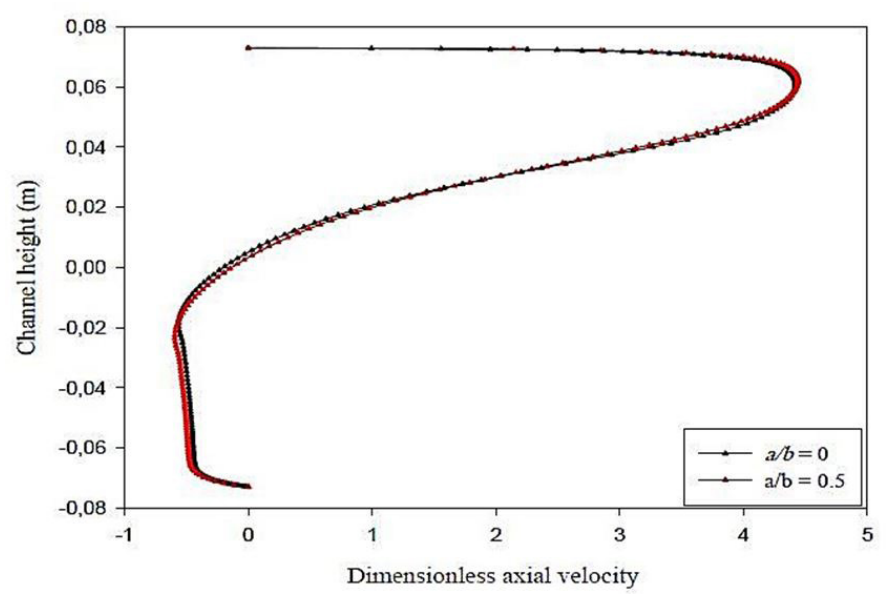

Fig. 8 Profiles of $U / U_{i n}$ after the second baffle, near the exit, $\mathrm{Re}=10,000$.

The velocity field is also affected by the Reynolds number as it appears in Fig. 9. Fig. 9a and b shows the variation of dimensionless axial velocity profiles with Reynolds number for both the simple and the cascaded obstacles at axial positions $x=$ $0.255 \mathrm{~m}$ and $x=0.525 \mathrm{~m}$, measured downstream of the entrance.

For a Reynolds number ranging from 10,000 to 30,000, we find that the airflow is accelerated in the direction from left to right (positive direction), increasing the size of the recirculation zones (negative direction), where by the length of these regions recycling is proportional to the increase in the flow Reynolds number. As the figures, the cascaded baffle performs greater axial velocity than the simple baffle for all Reynolds numbers used. This is because the use of the cascaded baffle can induce larger recirculation flow appearing behind the baffle than that of the simple baffle as can be seen from the $U / U_{\text {in }}$ plots in Figs. 6, 7, and 8.

\subsection{Heat transfer}

Fig. 10a and $\mathrm{b}$ shows the contour plots of temperature field for the two cases studied, $a / b=0$ and $a / b=0.5$, at $\operatorname{Re}=10,000$, respectively. The analysis of the isotherms shows a reduction in temperature in the area situated between the top of each baffle and the channel walls. In the region downstream of the two baffles, there are cells with a recycling of relatively high temperature. Due to changes in the direction of the flow produced by the baffle, the value of the highest temperature appears behind the lower wall of the channel with the acceleration process that starts just after the second baffle. It is clear that for high velocity values, temperatures drop significantly. In other words, it exists an inverse proportionality between increasing Reynolds number and the total temperature in each channel cross section. These results can we certify that the heat exchange between the fluid and the walls in our study is higher with low Reynolds numbers. It addition, according to analysis of our numerical results on axial velocity (see Fig. 4), and the temperature fields for the whole domain investigated, it is found that the temperature of the fluid is related to the velocity of flow.

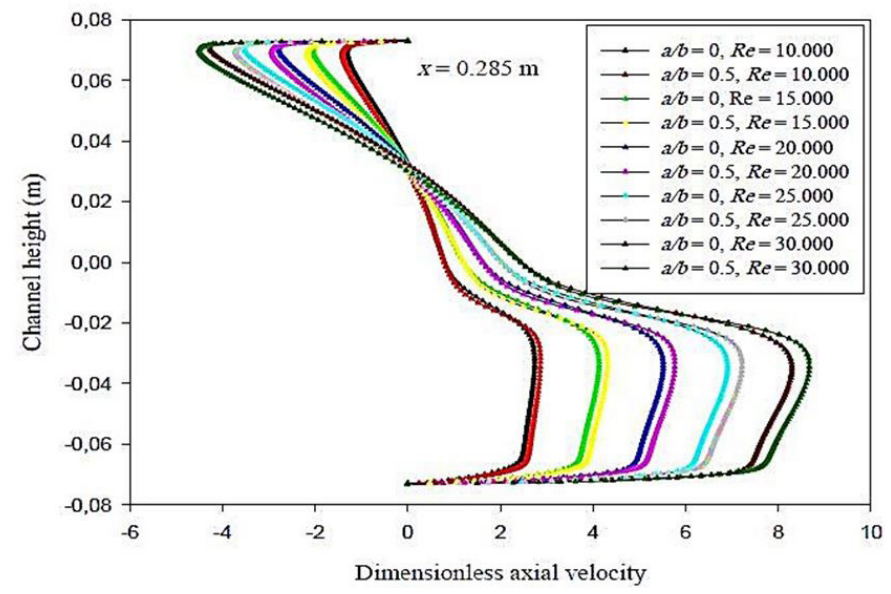

(a)

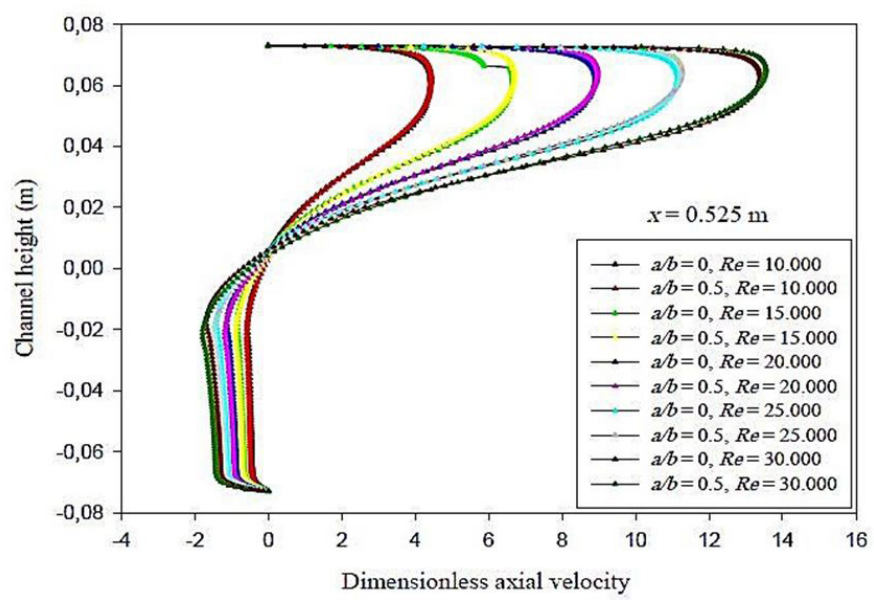

(b)

Fig. 9 Variation of $(U / U i n)$ profiles with Re number at stations: a) $x=0.285 \mathrm{~m}$ and b) $x=0.525 \mathrm{~m}$ from entrance.

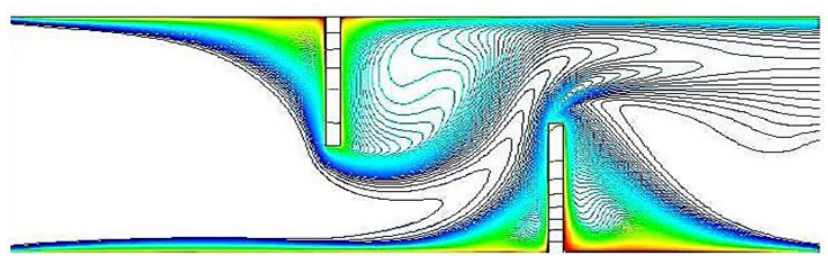

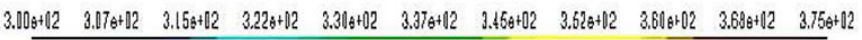

(a)

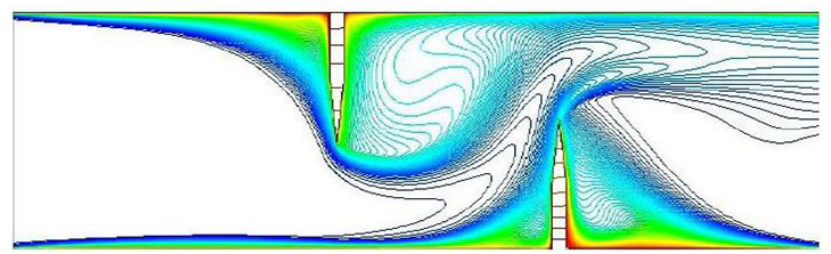

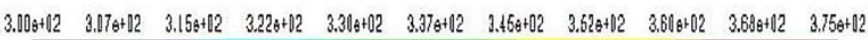

(b)

Fig. 10 Distribution of temperature field along the channel for a) simple and b) cascaded baffles at $\mathrm{Re}=10,000$ 
The fluid temperature profiles are shown in Figs. 11-13, for a Reynolds number of 10,000 at various cross-sections of the channel, $x=0.159,0.189,0.255,0.285$, and $0.525 \mathrm{~m}$; they are identical to those shown in the figures above. It is also observed that the section close to the baffle is better heated than the distant one.

Fig. 14 shows the numerical results of normalized local Nusselt number $\left(N u_{x} / N u_{0}\right)$ distributions at the upper wall of the channel with two models of baffles (simple and cascaded-shaped) when $\mathrm{Re}=10,000$. The local Nusselt number, $N u_{x}$ is calculated from their definition as given in Eq. (5). Nu is the Nusselt number for turbulent flow in a smooth channel at the same Re number, and is given by [25]. The trends of $N u_{x} / N u_{0}$ are similar for both models of baffles investigated. The normalized local Nusselt numbers show the smallest value in the region around the first heated upper channel wall-mounted baffle and the largest value in the region opposite the second lower wall-attached baffle for the two cases treated. The upper $N u_{x} / N u_{0}$ values near the tip of the second baffle are due to the

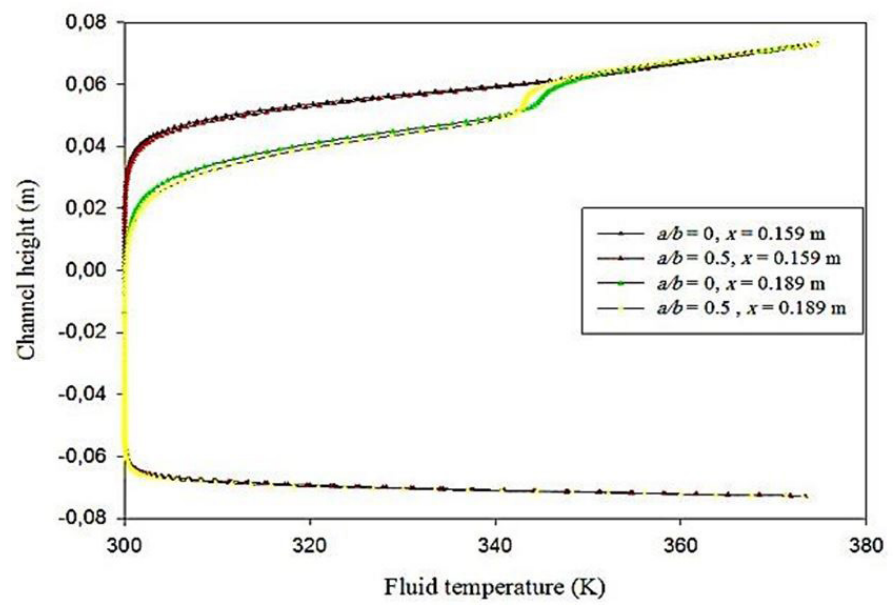

Fig. 11 Profiles of fluid temperature upstream of the first baffle at axial stations equal to $x=0.159 \mathrm{~m}$ and $x=0.189 \mathrm{~m}$ for the lowest Reynolds number value.

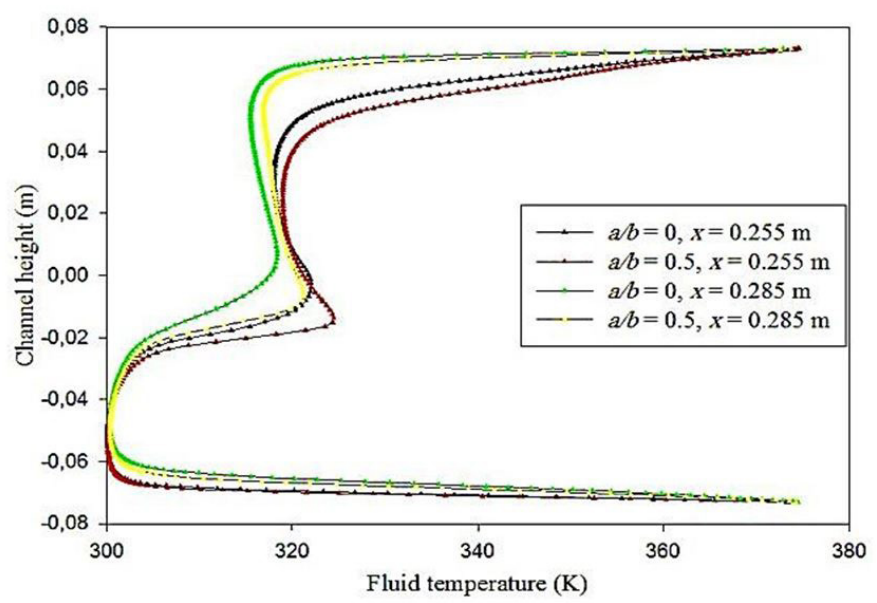

Fig. 12 Profiles of fluid temperature between the first and the second baffles at axial locations equal to $x=0.255 \mathrm{~m}$ and $x=0.285 \mathrm{~m}$ for the lowest Reynolds number value. strong temperature gradients in that region. The figure also shows that in the region downstream of both baffles, the local Nusselt number is enhanced [6]. This enhancement is due to the intense mixing by the recirculation cells [6]. The $N u_{x} / N u_{0}$ value decreases gradually in the region downstream of the recirculation, near the channel outlet, where the effect of the recirculation mixing is diminishing [6]. These remarks are confirmed numerically by Nasiruddin and Kamran Siddiqui [6], and Sripattanapipat and Promvonge [21].

To increase the Reynolds number of the flow, the velocity of the airflow at the entrance of the channel was increased. This acceleration causes the increased the size of the recycling zones (see Fig. 9) and consequently the Nusselt number rate is found strongly affected by the change of the Reynolds number, as shown in Fig. 15. It was found that the highest rate of heat transfer is achieved by increasing the Reynolds number where the flow structure very disturbed which promotes mixing of the fluid. On each baffle model, when the Reynolds number increases from 10,000 to 30,000 , the Nusselt number

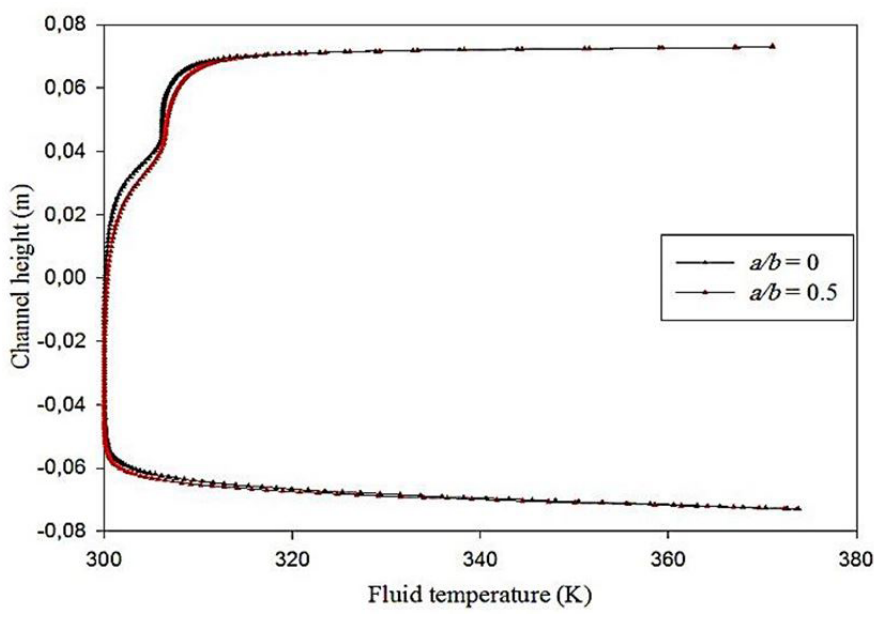

Fig. 13 Profiles of fluid temperature behind the second baffle at $x=0.525 \mathrm{~m}$ for the lowest Reynolds number value.

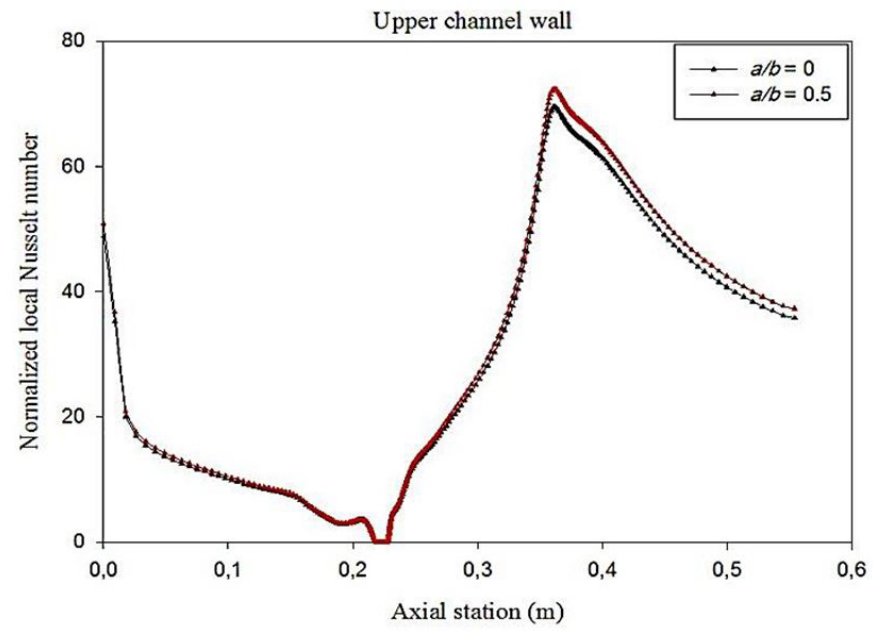

Fig. 14 Axial variation of $N u_{x} / N u_{0}$ along the upper channel wall for the two investigated baffle, $\mathrm{Re}=10,000$. 


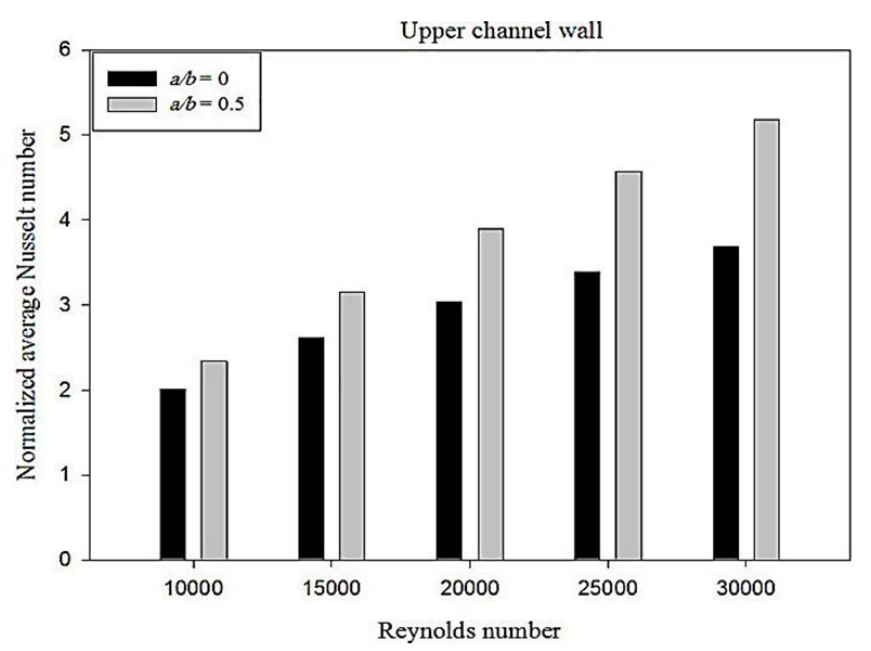

Fig. 15 Evaluation of normalized average Nusselt number as a function of Reynolds number for various cases applied.

believed, where we also find that the temperature gradient at the level of the heated walls decreases with increasing flow rate. As the figure, the baffle of cascaded rectangular-triangular form performs greater heat transfer rate than the simple baffle. The reason of this may be that the cascaded baffle can produce stronger impinging flow than the simple baffle. Over the range examined, the CRTB increases the average heat transfer rate by $16.209-40.403 \%$ than the simple baffles. The $N u / N u_{0}$ value for CRTBs is found to be about 2.34-5.18 times over the plain channel with no baffle depending on the Re values.

\subsection{Pressure drop}

Fig. 16 presents the variation in the normalized skin friction coefficient $\left(C f / f_{0}\right)$ along the top wall of the channel for the simple $(a / b=0)$ and cascaded $(a / b=0.5)$ cases at $\operatorname{Re}=10,000$. Skin friction coefficient $\left(C_{f}\right)$ is calculated from their definition as given in Eq. (3). The $f_{0}$ is the friction factor in a smooth channel at the same Reynolds number, and is given by [26]. The results show that the values of the coefficient of skin friction is very low near the first baffle especially in upstream areas, this may be caused by the absence of baffle as obstacles. However, the skin friction coefficients are increased again at the stations corresponding to the region of recirculation which then results in an abrupt change in direction of flow as seen in the figure. We also note that the highest values of friction coefficient are situated in the output of the channel; these values correspond to significant pressure drops which are caused by the effect of the expansion of the air leaving the section formed by the second baffle and the top wall.

The numerical results shown in Fig. 16 show the impact of the obstacle form geometry on the normalized friction coefficient for a $R e$ value of 10,000 . However, it is also important to examine the impact of the $R e$ variation on this parameter. The flow was simulated for the Reynolds number of 10,000, 15,000, 20,000, 25,000, and 30,000.

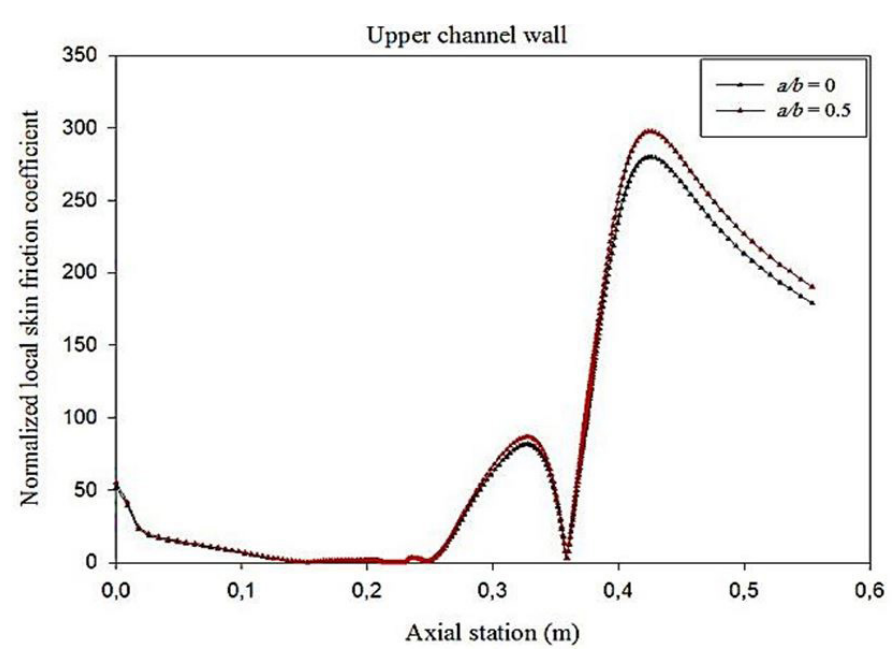

Fig. 16 Axial variation of $C f / f_{0}$ along the upper channel wall for the two investigated baffle, $\mathrm{Re}=10,000$.

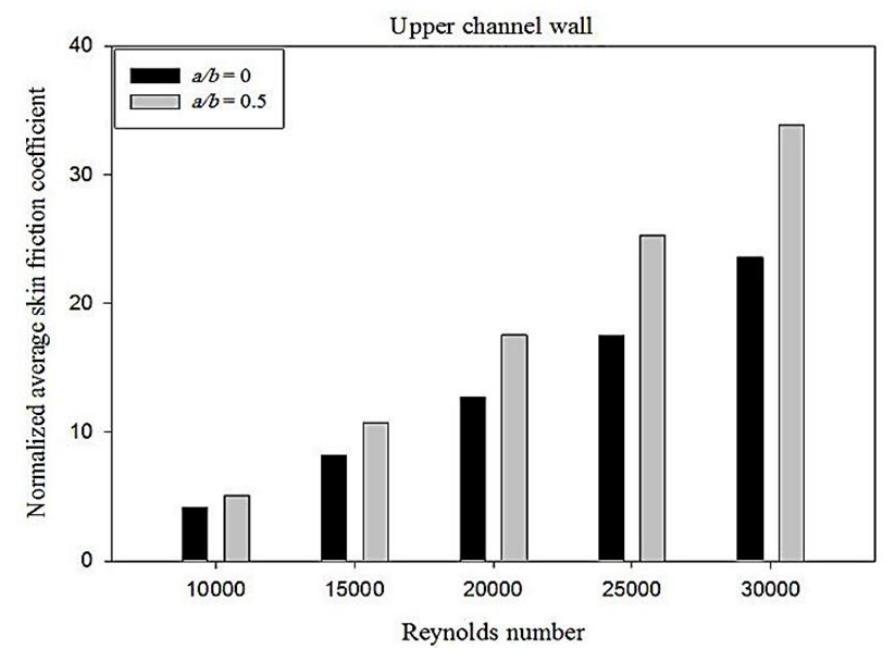

Fig. 17 Evaluation of normalized average skin friction coefficient as a function of Reynolds number for various cases applied.

Fig. 17 shows the normalized friction factor $\left(f / f_{0}\right)$ as a function of the Reynolds number. The friction factor distribution is defined by using Eq. (4). In the figure, it is found that the CRTB yields substantial pressure drop with a similar trend in comparison with the simple baffle case and the $f / f_{0}$ increases with the increment of Re in flow.

These results are obtained because the increase in the Reynolds number increases the flow rate of introducing large areas of recycling, which leads to an acceleration of the air flow and also the coefficient of friction and consequently pressure drop. The higher friction loss can be seen at the CRTB case $(a / b=0.5)$. This is because the use of the CRTB can induce larger recirculation appearing behind the obstacle than that of the flat baffle as can be seen from the $U / U_{\text {in }}$ plots in Fig. 9.

The friction factor is around, respectively, 4.103-23.606 and 5.063-33.825 times above the smooth rectangular pipe for the simple and cascaded baffles, depending on the Re values. 


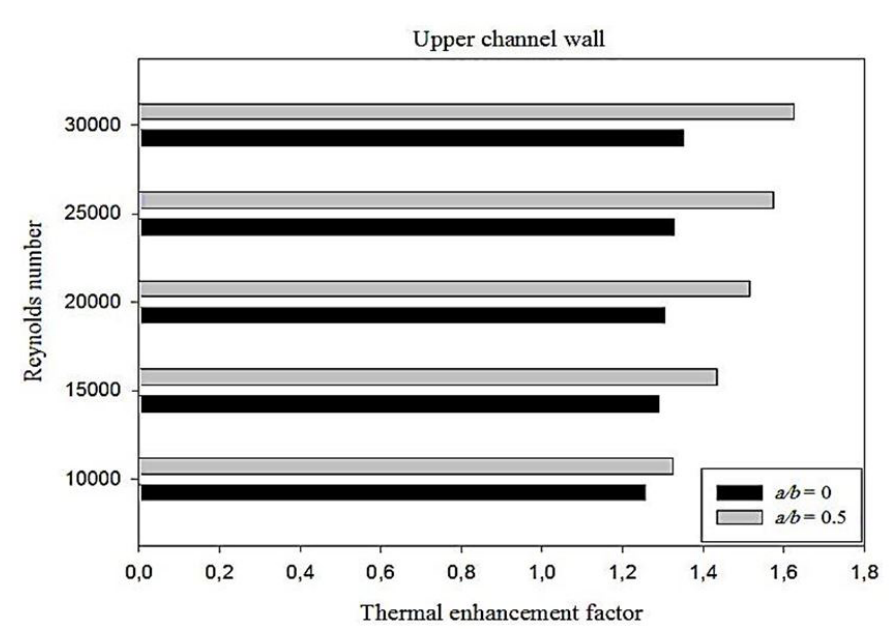

Fig. 18 Evaluation of Thermal enhancement factor as a function of Reynolds number for various cases examined.

\subsection{Thermal enhancement factor}

Fig. 18 shows the evolution of the thermal enhancement factor (TEF), calculated by Eq. (7), as a function of Reynolds number $(\operatorname{Re}=10,000,15,000,20,000,25,000$, and 30,000) with a constant section of the cascade-baffles for the upper surface of the channel. As expected, the thermal enhancement factor increases with the increase in the Reynolds number in both studied cases (flat rectangular or simple, and cascaded rectangular-triangular shaped baffles). The $T E F$ values range from 1.256, in the case of simple baffles for the lowest value of the Reynolds number (10,000), to 1.625 in the case of cascaded rectangular-triangular shaped baffles for the maximum value of the Reynolds number $(32,000)$. This value decreases by $20.246 \%$ for the case of simple baffles.

\section{Conclusion}

In this paper, we reported a computational fluid dynamical analysis on fluid flow and heat transfer through a constant temperature-surfaced rectangular cross section channel with transverse, staggered, cascaded rectangular-triangular, solid-type baffles (CRTBs) in the turbulent regime from $\mathrm{Re}=10,000$ to 30,000. The time-independent incompressible Reynolds- Averaged Navier-Stokes (RANS) and the energy equations were integrated through the finite volume method (FVM), by means of Computational Fluid Dynamics (CFD), Commercial software FLUENT with the SST $k$ - $\omega$ model to describe the turbulence phenomenon. Effects of different Reynolds numbers on the dynamic and thermal behavior of the air inside the channel are examined and the results of the CRTB are also compared with those of the simple baffle. In particular, velocity and temperature fields, profiles of dimensionless axial velocity, profiles of fluid temperatures, normalized local and average heat transfer coefficients, profiles and the distribution of the normalized skin friction coefficients, as well as thermal enhancement factors were obtained for all the whole domain treated and chosen for different locations at constant wall temperature condition along the upper and lower walls of the channel. The insertion of CRTBs in the channel with $a / b=0.5$ causes a much high friction loss, $f / f_{0}=5-33$ times but also provides a considerable heat transfer rate increase in the channel, $N u / N u_{0}=2-5$ times, depending on the Re numbers.

\section{References}

[1] Patankar, S. V., Liu, C. H., Sparrow, E. M. "Fully developed flow and heat transfer in ducts having streamwise-periodic variations of cross-sectional area" ASME Journal of Heat Transfer. 99, pp. 180-186. 1977. https://doi.org/10.1115/1.3450666

[2] Guo, Z., Anand, N. K. "Three-dimensional heat transfer in a channel with a baffle in the entrance region." Numerical Heat Transfer, Part A: Applications. 31(1), pp. 21-35. 1997. https://doi.org/10.1080/10407789708914023

[3] Demartini, L. C., Vielmo, H. A., Möller, S. V. "Numeric and experimental analysis of the turbulent flow through a channel with baffle plates. Journal of the Brazilian Society of Mechanical Sciences and Engineering. 26(2), pp. 153-159. 2004.

https://doi.org/10.1590/S1678-58782004000200006

[4] Mohammadi Pirouz, M., Farhadi, M., Sedighi, K., Nemati, H., Fattahi, E. "Lattice Boltzmann simulation of conjugate heat transfer in a rectangular channel with wall-mounted obstacles." Scientia Iranica B. 18(2), pp. 213-221. 2011.

https://doi.org/10.1016/j.scient.2011.03.016

[5] Mokhtari, M., Barzegar Gerdroodbary, M., Yeganeh, R., Fallah, K. "Numerical study of mixed convection heat transfer of various fin arrangements in a horizontal channel." Engineering Science and Technology, an Internation Journal. 20(3), pp. 1106-1114. 2017.

https://doi.org/10.1016/j.jestch.2016.12.007

[6] Nasiruddin, Kamran Siddiqui, M. H. "Heat transfer augmentation in a heat exchanger tube using a baffle." International Journal of Heat and Fluid Flow. 28(2), pp. 318-328. 2007.

https://doi.org/10.1016/j.ijheatfluidflow.2006.03.020

[7] Mellal, M., Benzeguir, R., Sahel, D., Ameur, H. "Hydro-thermal shellside performance evaluation of a shell and tube heat exchanger under different baffle arrangement and orientation." International Journal of Thermal Sciences. 121, pp. 138-149. 2017.

https://doi.org/10.1016/j.ijthermalsci.2017.07.011

[8] Dutta, P., Hossain, A. "Internal cooling augmentation in rectangular channel using two inclined baffles." International Journal of Heat and Fluid Flow. 26(2), pp. 223-232. 2005.

https://doi.org/10.1016/j.ijheatfluidflow.2004.08.001

[9] Guerroudj, N., Kahalerras H. "Mixed convection in a channel provided with heated porous blocks of various shapes." Energy Conversion and Management. 51(3), pp. 505-517. 2010.

https://doi.org/10.1016/j.enconman.2009.10.015

[10] Fodor, A. "Calculation of the temperature of boundary layer beside wall with time-dependent heat transfer coefficient." Periodica Polytechnica Mechanical Engineering. 54(1), pp. 15-20. 2010.

https://doi.org/10.3311/pp.me.2010-1.03

[11] Rábai, G., Vad, J. "Aerodynamic study on straight, arc-swept and twisted stationary linear cascade blades." Periodica Polytechnica Mechanical Engineering. 53(1), pp. 33-40. 2009.

https://doi.org/10.3311/pp.me.2009-1.05

[12] Hegedűs, F., Rákos, R., Kullmann, L. "Experimental and numerical study on cavitating vortex shedding behind a square cylinder." Periodica Polytechnica Mechanical Engineering. 53(2), pp. 55-60. 2009. https://doi.org/10.3311/pp.me.2009-2.01 
[13] Füle, P., Hernádi, Z. "Investigation of turbulent channel flow using local mesh refinement." Periodica Polytechnica Mechanical Engineering. 58(1), pp. 7-13. 2014.

https://doi.org/10.3311/PPme.7182

[14] Goda, R., Bánhidi, L. "Investigation of average air velocity and turbulence intensity in a slot ventilated space." Periodica Polytechnica Mechanical Engineering. 58(2), pp. 77-81. 2014.

https://doi.org/10.3311/PPme.7264

[15] Bidar, B., Shahraki, F., Mohebbi Kalhori, D. "3D Numerical Modelling of Convective Heat Transfer through Two-sided Vertical Channel Symmetrically Filled with Metal Foams." Periodica Polytechnica Mechanical Engineering. 60(4), pp. 193-202. 2016. https://doi.org/10.3311/PPme.8511

[16] Khrabry, A., Smirnov, E., Zaytsev, D., Goryachev, V. "Numerical Study of 2D and 3D Separation Phenomena in the Dam-Break Flow Interacting with a Triangular Obstacle." Periodica Polytechnica Mechanical Engineering. 60(3), pp. 159-166. 2016.

https://doi.org/10.3311/PPme.8948

[17] Fenyvesi, B., Horváth, Cs. "Investigation on the Non constant Behavior of a Vortex Flow Meter with Narrow Gauge Pipe via Conducting Measurements and Numerical Simulations." Periodica Polytechnica Mechanical Engineering. 61(3), pp. 247-254. 2017. https://doi.org/10.3311/PPme.10816

[18] Menni, Y., Azzi, A., Zidani, C., Benyoucef, B. "Numerical analysis of turbulent forced-convection flow in a channel with staggered 1-shaped baffles." Journal of New Technology and Materials. 6(2), pp. 44-55. 2016.

[19] Boonloi, A., Jedsadaratanachai, W. "Numerical investigation on turbulent forced convection and heat transfer characteristic in a square channel with discrete combined V-baffle and V-orifice." Case Studies in Thermal Engineering. 8, pp. 226-235. 2016. https://doi.org/10.1016/j.csite.2016.07.003
[20] Jedsadaratanachai, W., Boonloi, A. "Effects of blockage ratio and pitch ratio on thermal performance in a square channel with $30^{\circ}$ double V-baffles." Case Studies in Thermal Engineering. 4, pp. 118-128. 2014. https://doi.org/10.1016/j.csite.2014.08.002

[21] Sripattanapipat, S., Promvonge, P. "Numerical analysis of laminar heat transfer in a channel with diamond-shaped baffles." International Communications in Heat and Mass Transfer. 36(1), pp. 32-38. 2009. https://doi.org/10.1016/j.icheatmasstransfer.2008.09.008

[22] Lei, Y.-G., He, Y.-L., Chu, P., Li, R. "Design and optimization of heat exchangers with helical baffles." Chemical Engineering Science. 63(17), pp. 4386-4395. 2008.

https://doi.org/10.1016/j.ces.2008.05.044

[23] Menni, Y., Azzi, A., Zidani, C. "Use of waisted triangular-shaped baffles to enhance heat transfer in a constant temperature-surfaced rectangular channel." Journal of Engineering Science and Technology. 12(12), pp. 3251-3273. 2017.

[24] Sriromreun, P., Thianpong, C., Promvonge, P. "Experimental and numerical study on heat transfer enhancement in a channel with Z-shaped baffles." International Communications in Heat and Mass Transfer. 39(7), pp. 945-952. 2012.

https://doi.org/10.1016/j.icheatmasstransfer.2012.05.016

[25] Dittus, F. W., Boelter, L. M. K. "Heat transfer in automobile radiators of tubular type." University of California Publications in Engineering. Vol. 2, Berkeley, California, University of California Press, 1930. https://doi.org/10.1016/0735-1933(85)90003-X

[26] Petukhov, B. "Heat Transfer and Friction in Turbulent Pipe Flow with Variable Physical Properties." Advances in Heat Transfer. 6, pp. 503564. 1970. https://doi.org/10.1016/S0065-2717(08)70153-9

[27] Patankar, S. V. "Numerical heat transfer and fluid flow." Hemisphere, New York, 1980. 